\title{
Pengaruh Profitabilitas, Ukuran Perusahaan dan Leverage terhadap Praktik Perataan Laba
}

(Studi Kasus pada Perusahaan Properti dan Real Estate

yang terdaftar di Bursa Efek Indonesia tahun 2012-2017)

\section{The Influence of Profitability, Firm Size and Leverage on Income Smoothing}

(Studies on Property and Real Estate Company on

The Indonesia Stock Exchange 2012-2017)

\author{
${ }^{1}$ Yuniar Aemanah , 2 Deannes Isynuwardhana \\ ${ }^{12}$ Prodi S1 Akuntansi, Fakultas Ekonomi dan Bisnis, Universitas Telkom \\ 1yuniaraemanah@student.telkomuniversity.ac.id, ${ }^{2}$ deannes@telkomuniversity.ac.id
}

\begin{abstract}
Income smoothing is one of the strategies or business conducted by the company's management with the aim to reduce the fluctuations in earnings This is done with the motivation to show good performance to investors. This effort is made by playing with the income and the cost of the current period to be higher or lower than the actual income and expenses. Income smoothing is one form of earnings management.This study aims to determine the effect of independent variables in the form of profitability, firm size, and leverage to the practice of income smoothing in property and real estate companies listed on the Indonesia Stock Exchange 2012 to 2017. The method used in sampling this study using purposive sampling which produces 23 samples within the period of 6 (six years) of 138 sample units. The analytical method used is logistic regression analysis processed using SPSS 23. Based on the result of research, it is found that simultaneously profitability, firm size, and leverage variables influence the practice of income smoothing. Partially variable of firm size, and leverage do not have an effect on income smoothing, while profitability variable have positive and significant effect to income smoothing.
\end{abstract}

\section{Keywords: Income Smoothing, Profitability, Company Size, Leverage}

Abstrak. Perataan laba merupakan salah satu strategi atau usaha yang dilakukan manajemen perusahaan dengan tujuan untuk mengurangi fluktuasi laba agar laba terlihat lebih baik dimata para investor. Usaha ini dilakukan dengan mempermainkan pendapatan dan biaya periode berjalan menjadi lebih tinggi atau lebih rendah daripada pendapatan dan biaya sesungguhnya. Perataan laba merupakan salah satu bentuk dari manajemen laba. Penelitian ini bertujuan untuk mengetahui pengaruh variabel independen yang berupa profitabilitas, ukuran perusahaan, dan leverage terhadap praktik perataan laba pada perusahaan sektor properti dan real estate yang terdaftar di Bursa Efek Indonesia tahun 2012 sampai 2017. Metode yang digunakan dalam pengambilan sampel penelitian ini menggunakan purposive sampling yang menghasilkan 23 sampel dalam kurun waktu 6 (enam tahun) yaitu sebanyak 138 unit sampel. Metode analisis yang digunakan yaitu analisis regresi logistik yang diolah menggunakan SPSS 23.Berdasarkan hasil penelitian, diperoleh hasil bahwa secara simultan variabel profitabilitas, ukuran perusahaan, dan leverage berpengaruh terhadap praktik perataan laba. Secara parsial variabel ukuran perusahaan, dan leverage tidak 

berpengaruh terhadap perataan laba, sedangkan variabel profitabilitas berpengaruh positif dan signifikan terhadap perataan laba.

\section{Kata Kunci : Perataan Laba, Profitabilitas, Ukuran Perusahaan, Leverage}

\section{A. Pendahuluan}

Menurut Kasmir (2011) laporan keuangan merupakan sumber informasi atas kondisi keuangan suatu perusahaan yang diperlukan untuk memenuhi kebutuhan berbagai pihak, baik eksternal maupun internal perusahaan . Pada dasarnya laporan keuangan merupakan suatu ringkasan atau susunan daftar yang merupakan pertanggungjawaban manajemen perusahaan untuk menilai sejauh mana hasil kinerja atau prestasi perusahaan. Kieso and Weygandt (2011:3) menyatakan bahwa: "Laporan keuangan merupakan sarana pengkomunikasian informasi keuangan utama kepada pihak-pihak di luar korporasi”".

Perhatian pengguna laporan keuangan ataupun investor cenderung hanya terpusat pada informasi laba. Oleh karena itu, manajemen memiliki kecenderungan untuk melakukan tindakan yang dapat membuat laporan keuangan terlihat lebih sehat secara finansial, salah satunya adalah tindakan manajemen laba (Income Smoothing).Manajemen laba menurut Riahi dan Belkaoui (2011:74) yaitu suatu kemampuan untuk memanipulasi pilihan-pilihan yang tersedia dan mengambil pilihan yang tersedia yang tepat untuk dapat mencapai tingkat laba yang diharapkan. Davidson et al dalam Sulistyanto (2008: 48) menyatakan bahwa manajemen laba adalah proses untuk mengambil langkah tertentu yang disengaja dalam batasan-batasan prinsip akuntansi yang diterima umum untuk menghasilkan tingkat yang diinginkan dari laba yang dilaporkan.

Penelitian ini membahas bentuk manajemen laba perataan laba (income smoothing). Menurut Subramanyam dan Wild (2010:131) strategi perataan laba , manajer meningkatkan atau menurunkan laba yang dilaporkan untuk mengurangi fluktuasinya. Perataan laba juga mencakup tidak melaporkan bagian laba pada periode baik dengan menciptakan cadangan atau "bank" laba dan kemudian melaporkan melaporkan laba ini saat periode buruk, banyak perusahaan menggunakan bentuk laba ini. Adapun alasan manajemen untuk melakukan perataan laba yaitu, (1) Untuk memaksimalkan kegunaan dan kesejahteraannya. (2) Sebagai suatu fungsi keamanan pekerjaan, peringkat dan tingkat pertumbuhan gaji serta peringkat dan tingkat pertumbuhan ukuran perusahaan. (3) Sebagai kepuasan dari pemegang saham terhadap kinerja perusahaan meningkatkan status dan penghargaan dari para manajer. (4) Sebagai tingkat pertumbuhan dan stabilitas dari pendapatan perusahaan, (Gordon dalam Riahi dan Belkaoui,2011:193).

Profitabilitas merupakan kemampuan perusahaan dalam menghasilkan laba di masa depan. Ini didukung dengan hasil penelitian yang dilakukan oleh (Budiasih, 2009), proksi yang digunakan untuk mengukur profitabilitas yaitu Return On Asset (ROA). Perusahaan yang memiliki tingkat ROA yang tinggi lebih memungkinkan untuk melakukan tindakan perataan laba karena manajemen mengetahui kemampuan dalam mendapatkan laba di masa mendatang, sehingga memudahkan manajemen untuk mempercepat laba . Semakin tinggi tingkat Return On Assets (ROA) suatu perusahaan berarti perusahaan tersebut mempunyai kinerja yang bagus dalam menghasilkan laba bersih untuk pengembalian total aktiva yang dimiliki artinya tinggi rendahnya Return On Assets (ROA) akan mempengaruhi minat investor dalam melakukan investasi sehingga akan mempengaruhi volume penjualan saham perusahaan. 

Ukuran perusahaan adalah suatu skala dimana dapat diklasifikasikan menurut berbagai cara, antara lain: total aset, log size, nilai pasar saham, dan lain-lain. Penentuan ukuran perusahaan dalam penelitian ini didasarkan kepada total aset perusahaan, karena total aset dianggap lebih stabil dan lebih dapat mencerminkan ukuran perusahaan (Machfoedz, 1994; dalam Herawaty 2005). Hasil penelitian yang dilakukan oleh Dewi dan Sujana (2014) bahwa ukuran perusahaan memiliki pengaruh terhadap perataan laba hal ini berarti perusahaan- perusahaan yang berukuran besar lebih cenderung melakukan praktik perataan laba.

Leverage yang diukur dengan financial leverage menunjukkan proporsi penggunaan utang untuk membiayai investasinya. Financial Leverage menunjukkan sejauh mana aset perusahaan telah dibiayai oleh penggunaan hutang (Kasmir, 2011: 151). Semakin besar utang perusahaan maka semakin besar pula risiko yang dihadapi investor sehingga investor akan meminta tingkat keuntungan yang semakin tinggi. Akibat kondisi tersebut perusahaan cenderung untuk melakukan praktik perataan laba.

Berdasarkan faktor-faktor yang telah djelaskan dan terdapat beberapa inkonsistensi hasil penelitian pada penelitian-penelitian sebelumnya, maka penulis tertarik untuk melakukan penelitian lebih lanjut mengenai variabel-variabel tersebut dan melakukan penelitian mengenai praktik perataan laba pada perusahaan properti dan Real Estate. Untuk itu penulis memilih judul penelitian, "Pengaruh Profitabilitas, Ukuran Perusahaan, Leverage, Terhadap Praktik Praktik Perataan Laba (Studi Pada Perusahaan Properti dan Real Estate yang Terdaftar di Bursa Efek Indonesia tahun 2012-2017)".

\section{B. Landasan Teori Laporan Keuangan}

Sesuai yang tercantum dalam Standar Akuntansi Keuangan (PSAK) No. 1 (revisi 2015), yaitu: Tujuan laporan keuangan adalah memberikan informasi tentang posisi keuangan, kinerja, dan arus kas entitas yang bermanfaat bagi pengguna laporan keuangan dalam rangka membuat keputusan-keputusan ekonomi serta menunjukkan pertanggungjawaban manajemen atas pengguna sumber-sumber daya yang dipercayakan kepada mereka. Sehingga dapat disimpulkan bahwa laporan keuangan yaitu sumber informasi yang didalamnya menjelaskan mengenai kondisi keuangan sebuah perusahaan dimana bagian dalam laporan keuangan ini yang paling banyak dan paling teliti dilihat oleh investor dalam rangka mengetahui kinerja suatu perusahaan tersebut apakah kinerjanya baik atau buruk.

\section{Informasi Laba}

Laba dapat didefinisikan sebagai kenaikan aset dalam suatu periode akibat kegiatan produktif yang dapat dibagi atau distribusi kepada kreditor, pemerintah, pemegang saham (dalam bentuk bunga, pajak, dan dividen) tanpa mempengaruhi kebutuhan ekuitas pemegang saham semula, (Suwardjono, 2010:464).

\section{Manajemen Laba}

Davidson et al dalam Sulistyanto (2008: 48) menyatakan bahwa manajemen laba adalah proses untuk mengambil langkah tertentu yang disengaja dalam batasan-batasan prinsip akuntansi yang diterima umum untuk menghasilkan tingkat yang diinginkan dari laba yang dilaporkan. 



\section{Perataan Laba}

Menurut Sulistyanto (2008:177) perataan laba (income smooting) adalah upaya perusahaan mengatur agar labanya relatif sama selama beberapa periode. Tindakan perataan laba tidak dapat diketahui secara langsung namun untuk mengetahui perusahaan melakukan perataan laba dapat diukur dengan menggunakan indeks Eckel (1981). Indeks Eckel membedakan antara perusahaan yang melakukan perataan laba dengan perusahaan yang tidak melakukan perataan laba. Menurut (Gordon) dalam Widana dan Yasa (2013) laba yang digunakan dalam menghitung indeks Eckel adalah net income atau laba bersih. Berikut adalah rumus untuk mengitung indeks Eckel:

$$
\text { Indeks Perataan Laba }=\frac{\mathbf{C V} \Delta \mathbf{E A T}}{\mathbf{C V} \Delta \mathbf{A S}}
$$

Keterangan :
$\Delta \mathrm{EAT}=$ Perubahan laba bersih dalam satu periode
$\Delta S=$ Perubahan penjualan dalam satu periode
$\mathrm{CV}=$ Koefisien variasi dari variabel, yaitu strandar deviasi dibagi dengan rata-rata perubahan laba (I) atau penjualan (S)

Variabel dependen dalam penelitian ini bersifat indeks kualitatif dan disebut juga variabel dummy. Dengan demikian pengukuran yang dilakukan dengan memberi nilai 0 untuk perusahaan yang tidak melakukan perataan laba dan nilai 1 untuk perusahaan yang melakukan perataan laba. (Butar dan Sudarsi, 2012)

Dimana $\mathrm{CV} \Delta \mathrm{I}$ dan $\mathrm{CV} \Delta \mathrm{S}$ dapat dihitung sebagai berikut:

Keterangan :

$$
\mathrm{CV} \Delta \mathrm{EAT} \text { dan } \mathrm{CV} \Delta \mathrm{S}=\sqrt{\frac{\sum(\Delta \mathrm{X}-\Delta \overline{\mathrm{X}})^{2}}{n-1}}: \Delta \overline{\mathbf{X}}
$$
$\Delta \mathrm{X}=$ Perubahan penghasilan bersih atau laba (I) atau penjualan (S) antara tahun $\mathrm{n}-1$ dan tahun $\mathrm{n}$
$\Delta \overline{\mathrm{X}} \quad=\quad$ Rata-rata perubahan penghasilan bersih atau laba (I) atau Penjualan (S) antara tahun $\mathrm{n}-1$ dan tahun $\mathrm{n}$
$n=$ Banyaknya tahun yang diamati

Berdasarkan indeks eckel, perusahaan diklasifikasikan sebagai perusahaan perata laba apabila hasil dari pembagian $\mathrm{CV} \Delta \mathrm{I}$ dan $\mathrm{CV} \Delta \mathrm{S}$ kurang dari 1. Apabila perusahaan melakukan praktik perataan laba, maka akan diberi status 1, sedangkan apabila perusahaan tidak melakukan praktik perataan laba, maka akan diberi status 0 .

\section{Profitabilitas}

Menurut Yustriari dan Sujana (2014) Profitabilitas adalah Kemampuan perusahaan dalam menghasilkan laba selama periode tertentu. Dalam penelitian ini profitabilitas dinilai dengan rasio return on asset (ROA). ROA dapat dihitung dengan rumus sebagai berikut, (Widana dan Yasa, 2013) :

$$
\mathrm{ROA}=\frac{\text { laba setelah pajak }}{\text { Total aset }} \times 100 \%
$$





\section{Ukuran Perusahaan}

Menurut Ibrahim (2008) ukuran perusahaan merupakan gambaran besar kecilnya perusahaan yang ditentukan berdasarkan ukuran nominal. Dalam penelitian ini Ukuran perusahaan diukur menggunakan logaritma natural total aset perusahaan, (Butar Butar dan Sudarsih, 2012) :

\section{Leverage}

$$
\text { Ukuran Perusahaan }=\text { Ln }(\text { Total Aset })
$$

Menurut Fahmi (2011:72) rasio Leverage adalah mengukur seberapa besar perusahaan dibiayai dengan hutang. Dalam Penelitian ini Leverage diukur dengan Debt to Equity Ratio (DER), (Widana dan Yasa, 2013) :

$$
\text { Debt to Equity Ratio }=\frac{\text { Total Hutang }}{\text { Total Ekuitas }} \times 100 \%
$$

\section{Kerangka Pemikiran}

\section{Profitabilitas terhadap perataan laba}

Profitabilitas yaitu kemampuan perusahaan dalam menghasilkan laba dalam suatu periode tertentu, semakin tinggi suatu profitabilitas perusahaan maka perusahaan akan semakin baik kinerjanya. Dalam penelitian ini profitabilitas diwakili dengan menggunakan Return On Asset (ROA) sebagai rasio pengukurannya.

Untuk menarik investor dalam berinvestasi , pihak manajemen akan berusaha untuk meningkatkan profitabilitas perusahaan, akan tetapi jika suatu laba yang dihasilkan perusahan tidak sesuai dengan target yang ingin dicapai maka akan memicu pihak manajemen agar labatersebut sesuai dengan yang diharapkan. Artinya bahwa profitabilitas yang rendah akan memicu manajemen perusahaan untuk melakukan tindakan perataan laba agar kinerja perusahaan tersebut tidak dianggap gagal dalam mencapai tujuannya . Alasan lainnya adalah karena profitabilitas berhubungan langsung dengan laba yang dihasilkan suatu perusahaan, maka profitabilitas ada kemungkinan mempengaruhi perataan laba.

$\mathrm{H}_{2}$ : Profitabilitas berpengaruh positif dan signifikan secara parsial terhadap perataan laba pada perusahaan properti dan real estate yang terdaftar di BEI 2012 $-2017$

\section{Ukuran Perusahaan terhadap perataan laba}

Ukuran perusahaan salah satunya dapat diukur dengan total aset yang dimiliki perusahaan tersebut. Perusahaan dengan ukuran besar cenderung akan melakukann perataan laba dibandingkan dengan perusahaan berukuran kecil, ini dilakukan agar terhindar dari kenaikan pembebanan biaya oleh pemerintah, sebaliknya penurunan laba secara drastis memberikan sinyal bahwa perusahaan dalam masa krisis. Hal ini dapat mengundang campur tangan pemerintah.

$\mathrm{H}_{3}$ : Ukuran Perusahaan berpengaruh positif dan signifikan secara parsial terhadap perataan laba pada perusahaan properti dan real estate yang terdaftar di BEI 2012 2017

\section{Leverage terhadap perataan laba}

Leverage yang salah satunya diukur dengan Debt to Equity Ratio (DER) yang menggambarkan risiko struktur modal, dengan membandingkan dana dari kreditur 

dalam bentuk utang dengan investor dalam bentuk kekayaan (Fraser dan Ormiston 2004 dalam Widana dan Yasa 2013). Dalam hal ini DER berhubungan dengan hutang yang diberikan dari kreditur. Dimana Para kreditur memberikan hutang kepada perusahaan tersebut dengan melihat laba yang dihasilkan perusahaan. Perusahaan yang menghasilkan laba yang fluktuatif memiliki resiko yang besar yang akan ditanggung oleh kreditur jika uang yang dipinjamkan tidak tertagih atau tidak kembali. Karena hal tersebut pihak manajemen memiliki inisiatif untuk melakukan perataan laba.

Ramanuja dan Mertha (2015) menemukan bahwa DER mempunyai pengaruh positif dan signifikan terhadap praktik perataan laba diperusahaan. Dimana hasilnya menunjukkan bahwa, tingkat debt to equity rasio yang tinggi dapat mendorong suatu perusahaan untuk melakukan perataan laba. Hal ini menggambarkan kemampuan utang untuk mendanai aktivitas perusahaan dengan persentase ekuitas yang dimiliki perusahaan. Semakalin besar utang, maka akan semakin besar juga risiko yang dihadapi investor sehingga investor akan meminta tingkat keuntungan yang semakin tinggi.

\section{$\mathrm{H}_{4}$ : Leverage berpengaruh positif dan signifikan secara parsial terhadap perataan laba pada perusahaan properti dan real estate yang terdaftar di BEI 2012 $-2017$}

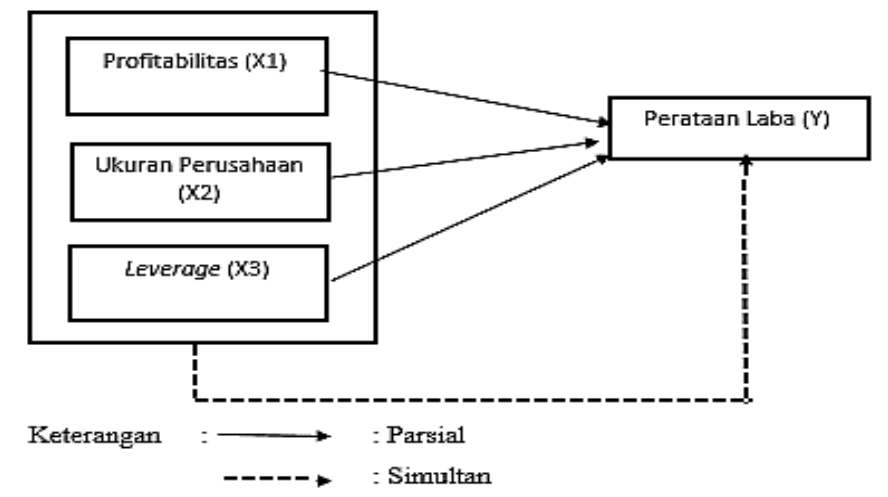

Gambar 1. Kerangka Pemikiran

\section{Metodologi}

Populasi yang digunakan dalam penelitian ini adalah perusahaan properti dan real estate yang terdaftar di Bursa Efek Indonesia pada tahun 2012-2017. Teknik pengambilan sampel yang digunakan penulis adalah sampling purposive. Dengan kriteria-kriteria yang digunakan dalam penentuan sampel adalah, 1). Perusahaan properti dan real estate yang terdaftar di Bursa Efek Indonesia selama periode penelitian antara tahun 2012-2017, 2). Perusahaan properti dan real estate yang konsisten terdaftar di Bursa Efek Indonesia tahun 2012-2017, 3). Perusahaan properti dan real estate yang memiliki laba positif tahun 2012-2017, 4). Perusahaan sektor properti dan real estate yang konsisten menerbitkan laporan keuangan yang diaudit selama periode penelitian 2012-2017. Dari kriteria tersebut diperoleh data obesrvasi sebanyak 138 yang terdiri dari 23 perusahaan dengan periode penelitian selama enam tahun. Teknik analisis yang digunakan dalam penelitian ini adalah analisis deskriptif dan analisis regresi logistik. Analisis regresi logistik yang persamaannya dapat dituliskan sebagai berikut:

$$
\mathrm{Y}=\alpha+\beta 1 \mathrm{X} 1+\beta 2 \mathrm{X} 2+\beta 3 \mathrm{X} 3+\mathrm{e}
$$



Keterangan:

$\mathrm{Y}=$ = Indeks income smoothing (variabel dummy, 1 untuk smoother, 0 untuk non smoother)

A $\quad=$ Konstanta

$\mathrm{X} 1=$ Profitabilitas diproksikan dengan ROA

$\mathrm{X} 2=$ Ukuran Perusahaan diproksikan dengan Ln Total aset

$\mathrm{X} 3=$ Leverage diproksikan dengan DER

$\beta 123=$ Koefisien Regresi

e $\quad=$ Standard Error

\section{Hasil Penelitian Dan Pembahasan}

Berikut ini hasil penelitian yang dilakukan oleh penulis, berdasarkan data dari tabel 1 dapat diketahui masing-masing nilai minimum, nilai maksimum, rata-rata (mean), dan standar deviasi untuk $\mathrm{N}$ (jumlah keseluruhan data) jumlah 138 dengan jumlah semua data valid.

- Analisis Statistik Deskriptif

Tabel 1

Statistik Deskriptif Variabel Independen

\begin{tabular}{|l|r|r|r|r|r|}
\hline & \multicolumn{1}{|c|}{$\mathrm{N}$} & Minimum & Maximum & \multicolumn{1}{c|}{ Mean } & $\begin{array}{c}\text { Std. } \\
\text { Deviation }\end{array}$ \\
\hline ROA & 138 & .0042 & .2539 & .065799 & .0457455 \\
\hline SIZE & 138 & 25.7928 & 31.0875 & 29.097438 & 1.3224628 \\
\hline DER & 138 & .0738 & 3.7010 & .8546 & .6572369 \\
\hline $\begin{array}{l}\text { Valid N } \\
\text { (listwise) }\end{array}$ & 138 & & & & \\
\hline
\end{tabular}

- Analisis Regresi Logistik

Tabel 2

Menilai kelayan model regresi

\begin{tabular}{|c|c|c|c|}
\hline \multicolumn{4}{|c|}{ Tabel 2.Hosmer and Lemeshow Test } \\
\hline Step & Chi-square & df & Sig. \\
\hline 1 & 7.520 & 8 & .482 \\
\hline
\end{tabular}

Sumber:Output Spss 23

Dari tabel 2 di atas menunjukkan hasil pengujian Hosmer and Lemeshow's, diperoleh nilai chi-square 7.520 dengan tingkat signifikansi 0.482 . Karena tingkat signifikansi hitung lebih besar dari 0,05 atau Sig $>\alpha(0,05)$, maka hipotesis nol diterima. Hal ini menunjukkan bahwa model dapat diterima sehingga pengujian hipotesis dapat diterima. 

- Menilai Model Fit

Tabel 3

Iteration Historya,b,c

\begin{tabular}{|l|l|r|r|}
\hline \multicolumn{2}{|l|}{} & \multirow{2}{*}{$\begin{array}{c}-2 \text { Log } \\
\text { Iteration }\end{array}$} & Coefficients \\
\cline { 4 - 4 } likelihood & Constant \\
\hline \multirow{2}{*}{ Step 0 } & 1 & 191.048 & .087 \\
\cline { 2 - 4 } & 2 & 191.048 & .087 \\
\hline
\end{tabular}

Sumber :Output Spss 23

Tabel 4

Iteration History ${ }^{a, b, c, d}$

\begin{tabular}{|l|l|r|r|r|r|r|}
\hline \multicolumn{2}{|c|}{} & \multirow{2}{*}{$\begin{array}{c}-2 \text { Log } \\
\text { Iteration }\end{array}$} & \multicolumn{4}{|c|}{ Coefficients } \\
\cline { 4 - 7 } & likelihood & Constant & ROA & \multicolumn{1}{c|}{ SIZE } & \multicolumn{1}{c|}{ DER } \\
\hline \multirow{3}{*}{ Step 1 } & 1 & 178.836 & 2.258 & 12.505 & -.105 & .076 \\
\cline { 2 - 7 } & 2 & 178.525 & 2.337 & 14.890 & -.112 & .066 \\
\cline { 2 - 7 } & 3 & 178.524 & 2.342 & 15.052 & -.112 & .065 \\
\cline { 2 - 7 } & 4 & 178.524 & 2.342 & 15.052 & -.112 & .065 \\
\hline
\end{tabular}

Sumber :Output Spss 23

Dari tabel 3, dihasilkan nilai -2Log Likelihood output blok 0 adalah sebesar 191,048 dan nilai -2Log Likelihood output blok 1 sebesar 178,524 Dari kedua hasil Iteration History ouput blok 0 ataupun blok 1, didapatkan bahwa terjadi penurunan nilai -2Log Likelihood. Menurut Santoso (2014:220) penurunan nilai -2Log Likelihood tersebut menunjukkan model regresi yang lebih baik. Dengan demikian $H_{0}$ diterima, dikarenakan model tersebut fit dengan data.

- Koefisien Determinasi (Model Summary)

Tabel 5

Model Summary

\begin{tabular}{|l|r|r|c|}
\hline Step & $\begin{array}{c}-2 \text { Log } \\
\text { likelihood }\end{array}$ & $\begin{array}{c}\text { Cox \& Snell } \\
\text { R Square }\end{array}$ & $\begin{array}{c}\text { Nagelkerke } \\
\text { R Square }\end{array}$ \\
\hline 1 & $178.524^{\mathrm{a}}$ & .087 & .116 \\
\hline
\end{tabular}

Sumber :Output Spss 23

Berdasarkan tabel 5 model summary hasil pengolahan data dengan menggunakan metode regresi logistik, maka dapat dilihat hasil koefisien determinasi yang dilihat dari Nagelkerke $R$ Square sebesar 0,116 atau 11,6\%. Hal ini menunjukkan kombinasi variabel independen yaitu Profitabilitas yang diukur dengan ROA, Ukuran perusahaan yang diukur dengan total aset dan leverage yang diukur dengan DER mampu menjelaskan variasi dari variabel dependen yaitu kondisi perataan laba sebesar 11,6\% sedangkan sisanya yaitu $88,4 \%$ oleh faktor lain yang tidak diikutsertakan dalam model. 



\section{- Pengujian Simultan ( Omnibus Test of Model Coefficients)}

Tabel 6

Omnibus Tests of Model Coefficients

\begin{tabular}{|l|l|r|r|r|}
\hline \multicolumn{2}{|c|}{} & Chi-square & \multicolumn{1}{c|}{ df } & \multicolumn{1}{c|}{ Sig. } \\
\hline \multirow{3}{*}{ Step 1 } & Step & 12.524 & 3 & .006 \\
\cline { 2 - 5 } & Block & 12.524 & 3 & .006 \\
\cline { 2 - 5 } & Model & 12.524 & 3 & .006 \\
\hline
\end{tabular}

Sumber :Output Spss 23

Dari hasil tabel 6 Menunjukan bahwa nilai Chi-Square yang diperoleh adalah sebesar 14,574 dengan degree of freedom $=3$, serta tingkat signifikansi yang dihasilkan adalah 0,006 atau sebesar $0,6 \%$. Hal ini berarti bahwa $(0,006<$ 0,05) dengan demikian hipotesis penelitian $\mathrm{H}_{0,1}$ ditolak atau hipotesis $\mathrm{H}_{\mathrm{a}, 1}$ diterima yang berarti bahwa secara simultan variabel independen yang berupa profitabilitas, ukuran perusahaan, dan leverage memiliki pengaruh terhadap variabel dependen yaitu perataan laba pada perusahan properti dan real estate.

- Menilai Pengaruh Profitabilitas, Ukuran Perusahaan, dan Leverage secara Parsial terhadap Perataan Laba

Tabel 7

Variables in the Equation

\begin{tabular}{|l|l|r|r|r|r|r|r|}
\hline \multicolumn{2}{|c|}{} & \multicolumn{1}{|c|}{ B } & \multicolumn{1}{c|}{ S.E. } & \multicolumn{1}{c|}{ Wald } & \multicolumn{1}{c|}{ df } & \multicolumn{1}{c|}{ Sig. } & \multicolumn{1}{c|}{$\operatorname{Exp(B)}$} \\
\hline \multirow{3}{*}{$\begin{array}{l}\text { Step } \\
1^{\text {a }}\end{array}$} & ROA & 15.052 & 4.829 & 9.717 & 1 & .002 & 3445122.016 \\
\cline { 2 - 8 } & SIZE & -.112 & .137 & .677 & 1 & .411 & .894 \\
\cline { 2 - 8 } & DER & -.065 & .323 & .041 & 1 & .840 & 1.067 \\
\cline { 2 - 8 } & Constant & 2.342 & 3.905 & .360 & 1 & .549 & 10.407 \\
\hline
\end{tabular}

Sumber:Output Spss 23

Pada tabel 7, menunjukkan nilai sig dari profitabilitas (ROA) sebesar 0,002 , dimana nilai tersebut lebih kecil jika dibandingkan dengan nilai signifikan $(\alpha)=0,05$. Hal ini berarti terdapat pengaruh yang signifikan antara ROA terhadap praktik perataan laba.

Nilai sig dari ukuran perusahaan (SIZE) adalah sebesar 0, 411, dimana nilai tersebut lebih besar jika dibandingkan dengan nilai signifikan $(\alpha)=0,05$. Hal ini berarti tidak terdapat pengaruh yang signifikan antara ukuran perusahaan terhadap praktik perataan laba.

Variabel leverage (DER) adalah sebesar 0,840 , dimana nilai tersebut lebih besar jika dibandingkan dengan nilai signifikan $(\alpha)=0,05$. Hal ini berarti tidak terdapat pengaruh yang signifikan antara leverage terhadap praktik perataan laba.

Dari hasil pengujian tersebut maka diperoleh persamaan model regresi sebagai berikut:

$$
\mathrm{IS}=2,342+15,052 \mathrm{ROA}-0.112 \mathrm{SIZE}+0,065 \mathrm{DER}+e
$$





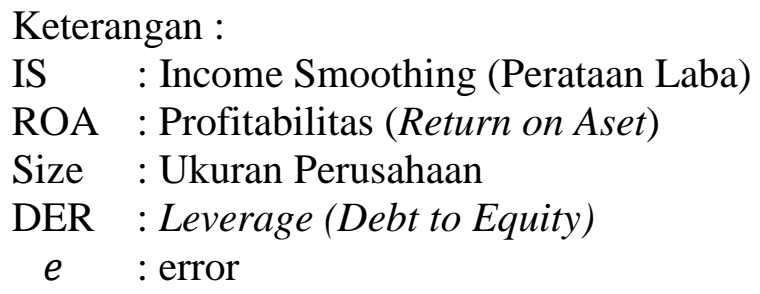

Penjelasan dari persamaan diatas sebagai berikut :

- Nilai Konstanta adalah sebesar 2,342, menunjukan bahwa apabila variabel profitabilitas, ukuran perusahaan, dan leverage diasumsikan konstan atau sama dengan 0 , maka kemungkinan praktik perataan laba perusahaan akan bernilai 2,342.

- Koefisien regresi $\beta_{1}$ 15,053 menyatakan bahwa setiap penambahan 1 satuan profitabilitas (dengan asumsi variabel lain konstan) maka akan meningkatkan kemungkinan praktik perataan laba sebesar 15,053.

- Koefisien regresi $\beta_{2}-0,112$ menyatakan bahwa setiap penambahan 1 satuan ukuran perusahaan (dengan asumsi variabel lain konstan) maka akan menurunkan kemungkinan praktik perataan laba sebesar 0,112 .

- Koefisien regresi $\beta_{3} 0,065$ menyatakan bahwa setiap penambahan 1 satuan leverage (dengan asumsi variabel lain konstan) maka akan menurunkan kemungkinan praktik perataan laba sebesar 0,065.

\section{E. Kesimpulan}

Kesimpulan dalam penelitian ini adalah : Secara simultan profitabilitas, ukuran perusahaan dan Leverage bersama-sama berpengaruh secara signifikan sebesar 11,6\% terhadap perataan laba pada perusahaan sektor properti dan real etate tahun 2012-2017. Secara parsial, hanya profitabilitas yang berpengaruh secara positif terhadap perataan laba pada perusahaan sektor properti dan real etate tahun 2012-2017. Sedangkan ukuran perusahaan dan leverage tidak berpengaruh terhadap perataan laba pada perusahaan sektor properti dan real etate tahun 2012-2017.

\section{F. Daftar Pustaka}

Arens, Alvin A dan Loebbecke, James K. 2011. Auditing, an Integrated Approach. Seventh Edition. Upper Saddle River, New Yersey: Prentice-Hall, Inc.

Belkaoui, Ahmed Riahi.(2011).Accounting Theory (Buku 1).Edisi Kelima.Jakarta: Salemba Empat.

Belkaoui, Ahmed Riahi.(2011). Accounting Theory (Buku 2). Edisi Kelima. Jakarta: Salemba empat.

Butar, Linda Kurniasih Butar dan Sudarsi, Sri. (2012). Pengaruh Ukuran Perusahaan, Profitabilitas, Leverage dan Kepemilikan Institusional Terhadap Perataan Laba: Studi Empiris pada Perusahaan Food and Beverages yang Terdaftar di BEI. Dinamika Akuntansi, Keuangan, dan Perbankan Vol. 1, No. 2. (ISSN: 1979-4878)

Dewi dan Prasetiono,(2012). Analisis Pengaruh ROA, NPM, DER, dan SIZE Terhadap Praktik Perataan Laba. Diponegoro Journal Of Management Vol. 1, Nomor 2 (ISSN : 2337-3792) 

Dewi, Ratih Kartika. (2011). Analisa Faktor-Faktor yang mempengaruhi Praktik Perataan Laba (Income Smoothing) pada Perusahaan Manufaktur yang Terdaftardi BEI (2006-2009). Diponegoro Journal Of Management Vol. 1, Nomor 2 (ISSN : 2337-3792).

Dewi dan Sujana,(2014) . Pengaruh Ukuran Perusahaan dan Profitabilitas pada Praktik Perataan Laba Dengan Jenis Industri Sebagai Variabel Pemoderasi di Bursa Efek Indonesia. E-Journal Akuntansi Universitas Udayana. (ISSN: 2302 8556).

Keputusan Ketua Badan Pengawas Pasar Modal Dan Lembaga Keuangan Nomor: KEP11/PM/1997 Tentang Pedoman Mengenai Bentuk dan Isi Pernyataan Pendaftaran Penawaran Umum Oleh Perusahaan Menengah Atau Kecil.

Kieso, D. E., Weygandt, J. J., \& Warfield, T. D (2011). Intermediate Accounting Volume 1 IFRS Edition. United States of America : Wiley.

Marhamah (2016), Pengaruh Profitabilitas,, net profit margin, leverage dan ukuran perusahaandan reputasi auditor terhadap perataan laba . E Jurnal Akuntansi STIE Semarang, (2016) vol 8 No. 3 :ISSN : 2085-5656

Murhayati,(2013). Pengaruh Profitabilitas, Ukuran Perusahaan, Leverage Terhadap Praktik Perataan Laba pada Perusahaan Manufaktur yang Listing di Bursa Efek Indonesia tahun 2006-2010. Cendekia Akuntansi, Vol. 1 No. 3, (ISSN 2338-3593).

Nugroho, Chintya dan Kristiani, Farida Titik. (2013). Pengaruh profitabilitas, leverage, ukuran perusahaan terhadap perataan laba (studi penelitian pada perusahaan yang terdaftar dalam Jakarta Islamic Index 2010-2012). Jurnal Universitas Telkom: tidak diterbitkan.

Prasetya dan Rahardjo, (2013). Pengaruh Ukuran Perusahaan, Profitabilitas, Financial Leverage , Klasifikasi KAP, dan Likuiditas terhadap Perataan Laba. Diponegoro journal of accounting, Vol.2 No.4, (ISSN 2337-3806).

Pratiwi dan Handayani, (2014). Pengaruh Profitabilitas, Kepemilikan Manajerial dan Pajak Terhadap Praktik Perataan Laba. ISSN: 2252-6765

Putri, Alifia Yuliandri. (2016).Pengaruh Ukuran Perusahaan,Profitabilitas, dan Leverage terhadap Praktik Perataan laba (studi Kasus Pada Perusahaan Manufaktur Yang Terdaftar di Bursa efek Indonesia tahun 20122014).Skripsi.Bandung:Universitas Telkom

Rusmin, dkk.(2012). Income smoothing behaviour by Asian transportation firms. Managerial Auditing Journal, Vol. 28 Iss 1 pp. $23-44$

Santoso, Singgih. (2010). Statistik Multivariat Konsep dan Aplikasi dengan SPSS. Jakarta: Elex Media Computindo.

Santoso, Yoriska Tri. (2010). Analisis Pengaruh NPM, ROA, Company Size, Financial Leverage, dan DER Terhadap Praktik Perataan Laba Pada Perusahaan Property dan Real Estate yang Terdaftar di Bursa Efek Indonesia. Jurnal Akuntansi Fakultas Ekonomi Universitas Gunadarma.

Saeidi (2012). The Relationship between Income Smoothing and Income Tax and Profitability Ratios In Iran Stock Marke. Asian Journal of Finance \& Accounting Vol. 4,X No.1 (ISSN: 1946-052X)

Sekaran, Uma. (2011). Research Methods For Business Metodologi Penelitian Untuk Bisnis. Jakarta: Salemba Empat. 

Sekaran, U. (2014). Metode Penelitian Untuk Bisnis . Jakarta: Salemba Empat.

Selanasari, Widi. (2015). Analisis Determinan Praktik Income Smoothing Pada Perusahaan yang Terdaftar dalam Jakarta Islamic Index Periode 2009-2013. Skripsi.Bandung:Universitas Telkom

Subramanyam, K.R dan Wild, John J. (2010). Analisis Laporan Keuangan (Buku 1). Jakarta: Salemba Empat

Subramanyam, K.R dan Wild, John J. (2010). Analisis Laporan Keuangan (Buku 2). Jakarta: Salemba Empat.

Suharto dan Sujana, (2016). Pengaruh Nilai Saham, Profitabilitas, dan Pajak Penghasilan terhadap Perataan Laba pada Perusahaan Properti dan Real Estate. E-Jurnal Akuntansi Universitas Udayana, Vol.17.3, (ISSN: 2302-8556).

Sugiyono. (2011). Metode Penelitian Kuantitatif Kualitatif dan R\&D. Bandung: Alfabeta.

Sugiyono. (2012). Metode Penelitian Kuantitatif Kualitatif dan R\&D. Bandung: Alfabeta.

Sugiyono. (2013). Metode Penelitian Kombinasi (Mixed Methods). Penerbit: Alfabeta, Bandung.

Sugiyono, dan Husein Umar,(2002). Metode Penelitian Bisnis. Bandung: Alfabeta.

Sulistiawan, Dedhy. (2011). Creative Accounting Mengungkap Manajemen Laba dan Skandal Akuntansi. Jakarta: Salemba Empat.

Sulistyanto, Sri. (2008). Manajemen Laba : Teori dan Model Empiris. Jakarta : PT. Gramedia Widiasarana Indonesia.

Supriastuti, Sri dan warnanti, Asri. (2015). Ukuran Perusahaan, Winner/Loser Stock, Debt To Equity Ratio, Dividend Payout Ratio Pengaruh Terhadap Perataan Laba. Jurnal Paradigma Vol. 13, No. 01 (ISSN: 1693-0827).

Suwardjono. (2010). Teori Akuntansi: Pengungkapan dan Sarana Interpretatif. Edisi Ketiga. BPFE, Yogyakarta.

Widana,I Nyoman Ari dan Yasa, Gerianta Wirawan (2013). Perataan Laba Serta Faktor - Faktor Yang Mempengaruhinya Di Bursa Efek Indonesia. E Jurnal Akuntansi Universitas Udayana (2013): 297-317 ISSN : 2302-8556

Wijaya (2009). Analisis Praktik Perataan Laba pada Industri Real Estate dan Properti yang bereputasi baik di Bursa Efek Indonesia. Jurnal Akuntansi Kontemporer, Vol.1, No.2, ISSN: 2085-1189. 